\title{
Erratum to: Expyriment: A Python library for cognitive and neuroscientific experiments
}

\author{
Florian Krause • Oliver Lindemann
}

Published online: 24 January 2014

(C) Psychonomic Society, Inc. 2014

\section{Erratum to: Behav Res}

DOI 10.3758/s13428-013-0390-6

The first block of programming code in the 'Overview' section has erroneous indentation in the published version. Since indentation is a syntactic feature of the Python programming language, the published code example is not functional and will result in a runtime error when attempting to execute the code. The original code example is reproduced below.

\section{Overview}

Structure

expyriment.design

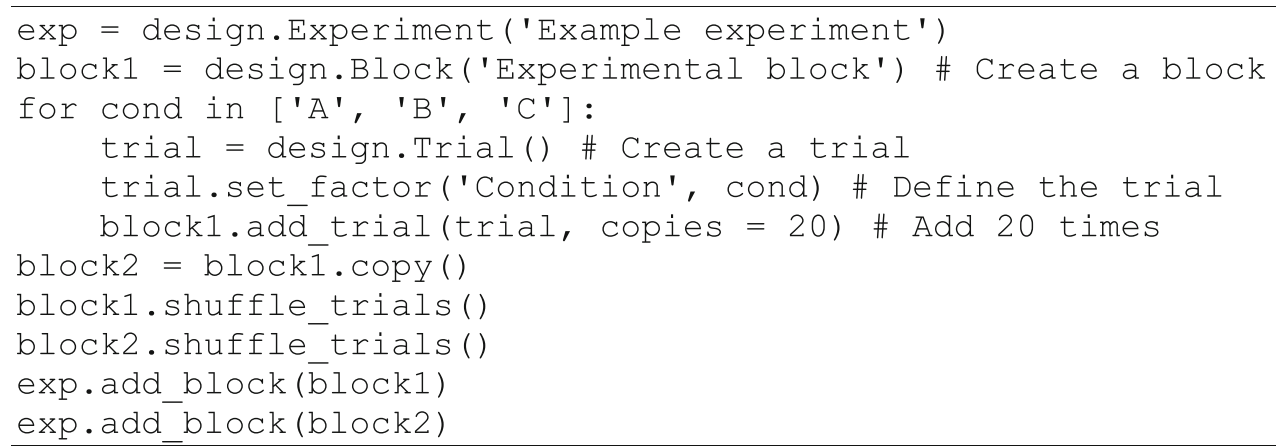

The online version of the original article can be found at http://dx.doi.org/ 10.3758/s13428-013-0390-6.

\section{F. Krause}

Donders Institute for Brain, Cognition and Behaviour, Radboud

University, Nijmegen, The Netherlands

O. Lindemann

Division of Cognitive Science, University of Potsdam, Potsdam,

Germany

F. Krause $(\bowtie)$

P.O. Box 9104, 6500 HE Nijmegen, The Netherlands

e-mail: f.krause@donders.ru.nl 